\title{
Correlation between echographic gastric emptying and appetite: influence of psyllium
}

\author{
J F Bergmann, O Chassany, A Petit, R Triki, C Caulin, J M Segrestaa
}

\begin{abstract}
The correlation between ultrasonographic gastric emptying and appetite was studied. Echographic evaluation of gastric emptying by measurement of the antral vertical diameter and assessment of sensations of hunger and satiety using analogue visual scales were performed simultaneously in 12 healthy volunteers. Measurements were carried out after the intake of $10.8 \mathrm{~g}$ psyllium or placebo in a randomised, crossover, double blind trial. The correlation between echographic gastric emptying and sensations of hunger and satiety was excellent $(\mathbf{p}<0.001)$ after the intake of either psyllium or placebo. Psyllium significantly delayed gastric emptying from the third hour after a meal. It increased the sensation of satiety and decreased hunger at the sixth hour after the meal. The association between echographic measurement and visual scales is a simple method of evaluating the relationship between the stomach and appetite. The pharmacodynamic effect of psyllium should be confirmed by longterm therapeutic trials.

(Gut 1992; 33: 1042-1043)
\end{abstract}

Real time ultrasound is a simple method of measuring gastric emptying which has been validated by previous studies.' Correlated with scintigraphic measurements, it could become the method of choice in evaluating the role of gastric distention in the regulation of appetite and assessing the efficacy of drugs on sensations of hunger and satiety. The main aim of this study was to determine whether there was a correlation between postprandial gastric volume measured by echography and the sensations of hunger and satiety evaluated by a validated visual analogue scale. ${ }^{2}$ The second aim was to assess whether, as a bulking agent, ${ }^{3}$ psyllium could modify echographic gastric emptying time and, in parallel, sensations of hunger and satiety.

Therapeutics Research Unit, Lariboisière

Hospital, Paris, France; Radiology Department, Lariboisière Hospital,

Paris, France

J F Bergmann

OChassany

A Petit

R Trik

J M Segrestaa

Correspondence to:

Dr J F Bergmann, Clinique

Thérapeutique, Hôpital

Lariboisière, 2 rue Ambroise

Paré, 75010 Paris, France.

Accepted for publication

18 November 1991 than their ideal weight gave written inform consent to the protocol which was approved by the ethics committee of the Hôpital Lariboisière. After fasting for four hours, at midday on the first day, the patients received three sachets each containing $3.6 \mathrm{~g}$ psyllium or three sachets of placebo dissolved in $100 \mathrm{ml}$ water. One minute later, the patients consumed a standard meal $(445 \mathrm{kcal}, 600 \mathrm{ml}, 40 \mathrm{~g}$ carbohydrates, $23 \mathrm{~g}$ lipids, $21 \mathrm{~g}$ proteins). Echographic evaluation of gastric emptying was obtained by measuring the prespinal vertical antral diameter just before the intake of drugs, and every hour over a six hour period, using an ATL Ultramark 4 ultrasound scanner equipped with a $3.5 \mathrm{MHz}$ probe.

Before and after eating the meal and every hour for six hours, the subjects were asked to record hunger sensations on a $100 \mathrm{~mm}$ vertical visual analogue scale, ${ }^{2+}$ placing crosses on lines representing ranges from 'not hungry at all' $=0$ to 'as hungry as possible' $=100$. The satiety sensation was recorded after the meal and every hour for six hours using the same kind of visual analogue scale with 'empty stomach' $=0$ and 'full' $=100$. They were also asked to record the time at which hunger returned. After a seven day washout period, the same measurements were taken under the same conditions after intake of the other treatment being studied. For the six hours after the test meal, the subjects were instructed to remain quiet.

Data are expressed as mean (SEM) analysis of variance (ANOVA), a bilateral paired $t$ test and linear correlation coefficients using $\mathrm{X}-\mathrm{Y}$ pairs were performed for statistical analysis.

\section{Results}

The trial was conducted in nine women and three men with a mean age of $43 \cdot 2(4 \cdot 3)$ years $(18-65)$ and a mean weight of $73.3(1 \cdot 8) \mathrm{kg}(68-85)$. All weighed at least $10 \%$ more than their ideal reference weight $(63.0(1 \cdot 3) \mathrm{kg})$.

As shown in the Figure, the correlation between the echographic measurements of gastric emptying and the visual analogue scale was excellent. This correlation was observed between gastric emptying and hunger during psyllium intake $(R=0.989, p=0.0001)$ or after placebo $(R=0.957, p=0.0007)$. It was also observed between gastric emptying and satiety during psyllium intake $(R=0.987, p=0.0001)$ or after placebo $(R=0.961, p=0.0006)$. This study confirmed that the decrease of the sensation of satiety is correlated with the increase of hunger.

Compared with placebo (ANOVA), psyllium slowed echographic gastric emptying from the third hour (Table). Between the third and sixth hour, the relative increase in gastric emptying time under psyllium was between $10 \%$ and $20 \%$ $(p<0.05)$. As far as the hunger and satiety sensations (Table) were concerned, a significant difference was only observed at the sixth hour with hunger being significantly more marked under placebo than under psyllium $(73(6) v 54$ (6), $p=0.05)$ and satiety more prolonged under 

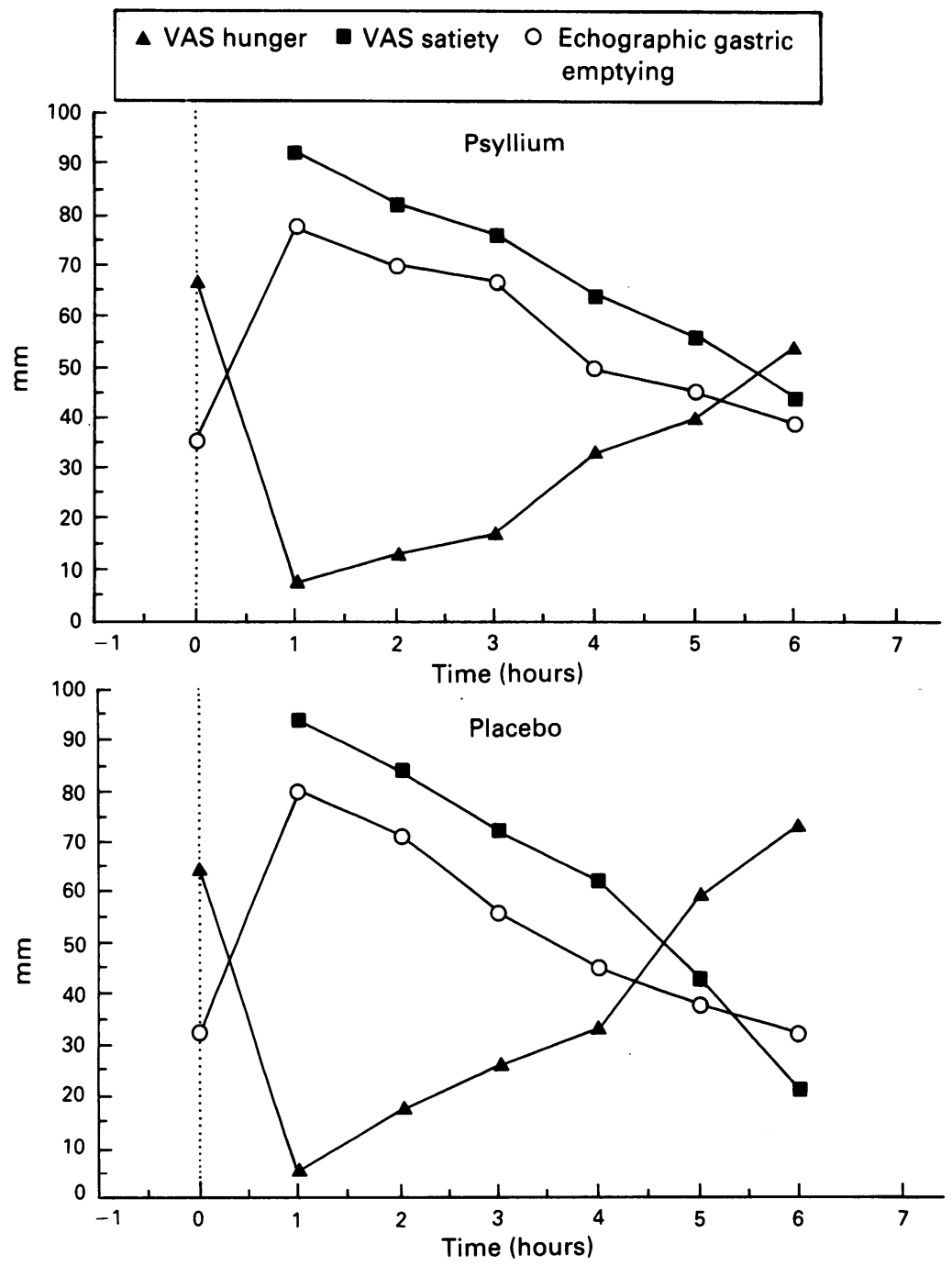

Simultaneous recording of echographic gastric emptying (antral vertical diameter), hunger and satiety (analogue visual scales -VAS) in 12 healthy volunteers over a six hour period after intake of a standard meal $(445 \mathrm{kcal})$. Measurement after intake of $10.8 \mathrm{~g}$ psylium and after placebo (crossover, double blind randomised study).

psyllium than under placebo (44 (7) $v 21(6)$, $\mathrm{p}=0.05)$. The absence of any period effect or period treatment interaction was checked.

The return of hunger after the test meal was slightly delayed by psyllium (342 (30) minutes $v$ $285(23)$ ) but the difference was not statistically significant.

During the course of the trial, one patient complained of regurgitation and another of diarrhoea, but in both cases these mild signs of intolerance occurred under placebo.

\section{Discussion}

The role of gastric distention in the regulation of appetite is well established. ${ }^{5}$ A simple, noninvasive method which could be used in clinical

Gastric emptying, hunger and satiety before and after the six hours after a standard meal eaten with psyllium $(10.8 \mathrm{~g})$ or placebo in 12 healthy subjects (mean (SEM))

\begin{tabular}{|c|c|c|c|c|c|c|c|c|c|}
\hline \multirow[b]{2}{*}{ Time $(h)$} & \multicolumn{3}{|c|}{$\begin{array}{l}\text { Echographic gastric emptying } \\
\text { Antral vertical diameter }(\mathrm{mm})\end{array}$} & \multicolumn{3}{|c|}{$\begin{array}{l}\text { Hunger } \\
\text { Visual analogue scale (mm) }\end{array}$} & \multicolumn{3}{|c|}{$\begin{array}{l}\text { Satiety } \\
\text { Visual analogue scale }(\mathrm{mm})\end{array}$} \\
\hline & Psyllium & Placebo & $p$ & Psyllium & Placebo & $p$ & Psyllium & Placebo & $p$ \\
\hline $\begin{array}{l}0 \\
1 \\
2 \\
3 \\
4 \\
5 \\
6\end{array}$ & $\begin{array}{l}35(7) \\
77(3) \\
70(3) \\
67(4) \\
50(3) \\
45(4) \\
39(3)\end{array}$ & $\begin{array}{l}32(6) \\
80(3) \\
71(3) \\
56(3) \\
45(3) \\
38(2) \\
32(2)\end{array}$ & $\begin{array}{l}N S \\
N S \\
N S \\
p=0.005 \\
p=0.09 \\
p=0.09 \\
p=0.09\end{array}$ & $\begin{array}{l}64(7) \\
7(4) \\
13(5) \\
17(6) \\
30(7) \\
40(7) \\
54(6)\end{array}$ & $\begin{array}{l}67(6) \\
5(1) \\
17(6) \\
26(6) \\
33(6) \\
59(8) \\
73(6)\end{array}$ & $\begin{array}{l}\text { NS } \\
\text { NS } \\
\text { NS } \\
\text { NS } \\
\text { NS } \\
\text { NS } \\
p=0.05\end{array}$ & $\begin{array}{l}\text { ND } \\
92(4) \\
82(5) \\
76(6) \\
64(7) \\
56(7) \\
44(7)\end{array}$ & $\begin{array}{l}\mathrm{ND} \\
94(2) \\
84(4) \\
72(5) \\
62(5) \\
43(8) \\
21(6)\end{array}$ & $\begin{array}{l}\text { NS } \\
\text { NS } \\
\text { NS } \\
\text { NS } \\
\text { NS } \\
\text { NS } \\
p=0.05\end{array}$ \\
\hline
\end{tabular}

pharmacology to monitor the close relationship between these two variables has so far been lacking. Our study clearly shows that a simple echographic measurement of the antral diameter correlates perfectly with sensations of hunger and satiety. Our echographic measurement of the antrum is too schematic for a physiological study of gastric motility but it is sufficient for use in crossover trials where each subject acts as his/ her own control. The reproducibility of the measurement and the correlation between antral surface, echographic gastric volume and scintigraphic measurements are well demonstrated. ${ }^{16}$ Our study confirms the reliability and validity of the visual analogue scale in short term trials. ${ }^{2}$ The combination of these two measurements could be very useful in studies involving food intake in obese patients and its pharmacological regulation and also provide a clearer understanding of the physiological relationship between the stomach and appetite.

In this study, we found that in obese patients psyllium moderately but significantly delays gastric emptying of a solid meal. This is associated with an extension of the duration of satiety and a delay in the appearance of hunger. Like pectin, ${ }^{7}$ psyllium forms a gel which is not digested or absorbed, thereby increasing the viscosity of the meal. By slowing gastric emptying, ${ }^{8}$ it increases the duration of gastric distention which explains the persistent impression of satiety at the sixth hour. This short, single dose study, however, is not sufficient to confirm the therapeutic value of psyllium in the longterm reduction of food intake in overweight patients, but by delaying the return of hunger, it could help patients to comply with diets.

In conclusion, we have shown that it is simple to simultaneously measure echographic gastric emptying and sensations of hunger and satiety. Perfectly correlated among themselves, these measurements allow us to propose a simple and non-invasive model for use in clinical pharmacology. It has been shown that with psyllium that a drug which delays the gastric emptying induces changes in the sensations of satiety and hunger. A single dose of psyllium has a moderate effect on gastric emptying and appetite, but further research is needed to define its efficacy on weight loss.

1 Bolondi L, Bortolotti M, Santi V, Calleti T, Gaiani S, Labo G. Measurement of gastric emptying by real-time ultrasonography. Gastroenterology 1985; 89: 752-9.

2 Silverstone T. Measurement of hunger and food intake in man. In: Silverstone T, et al, eds. Drugs and appetite. London: In: Silverstone T, et al, eds. Drugs and appetite. London:
Academic Press, 1982: 81-92.

3 Corinaldesi R, Stanghellini V, Bocci G, Galassi A, Pratico A, Miglioli M. Dietary fibres and intestinal transit times. Current Therap Res 1982; 31: 173-80.

4 Wilmshurst P, Crawley JCW. The measurement of gastric transit time in obese subjects using ${ }^{24} \mathrm{Na}$ and the effects of energy content and guar gum on gastric emptying and satiety. BrF Nutr 1980; 44: 1-6.

5 Quartermain D, Kissileff M, Shapiro R, Miller NE. Suppression of food intake with intragastric loading: relation to natural feeding cycle. Science 1971; 173: 941-3.

6 Dapoigny M, Bonnafous J, Delasalle P, Abergel A, Pelissier E, Veyre A, et al. Validation d'une méthode echographique de mesure de la vidange gastrique chez l'homme. Gastroenterol Clin Biol 1991; 15: 199-203.

7 Lorenzo DC, Williams C, Hajnal F, Valenzuela J. Pectin delays gastric emptying and increases satiety in obese subjects. Gastroenterology 1988; 95: 1211-5.

8 Ehrlein HG, Prove J. Effect of viscosity of test meals on gastric emptying in dogs. Q F Exp Physiol 1982; 67: 419-25.

9 Durrant $M$, Royston $P$. Short term effects of energy density on salivation, hunger and appetite in obese subjects. Int $\mathcal{f}$ Obes 1979; 3: 335-47. 